\title{
Bladder Neck Collagen Injection in the Treatment of Congenital Retrograde Ejaculation: A Case Report
}

\author{
Basri Cakiroglu ${ }^{1}$, Orhun Sinanoglu ${ }^{2}$, Ersan Arda ${ }^{3}$

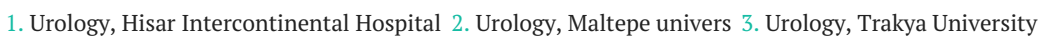

Corresponding author: Basri Cakiroglu, drbasri@gmail.com

\begin{abstract}
The present study describes the first successful treatment of a congenital retrograde ejaculation case with a submucosal collagen injection to the bladder neck.

A 28-year-old male (height $170 \mathrm{~cm}$, weight $80 \mathrm{~kg}$ ) attended to the urology outpatient clinic with complaints of scattered urine stream and absence of ejaculation. The laboratory tests, including hormone profile (follicle stimulating hormone, luteinizing hormone, and testosterone) and the routine blood count were within normal ranges, whereas semen analysis demonstrated a total absence of ejaculation. The analysis of post-ejaculate urine specimens revealed an elevated sperm concentration indicative of retrograde ejaculation. The cystoscopy was performed; the prostatic urethra was normal, the verumontanum was in the orthotopic position, and the bladder neck was wide opened. Dextranomer/hyaluronic acid copolymer (Deflux, $8 \mathrm{ml}$ ) was injected into the bladder neck at clock positions of one, five, seven, and 11 o'clock. During the same procedure, the large opening in the vesical collum was obliterated. During the first follow-up (four weeks after surgery), the patient was able to produce a normal ( $2.8 \mathrm{ml})$ ejaculation volume. The sperm analysis revealed normozoospermia, with 25 million spermatozoa/ml, 26\% (a) and 57\% (a + b) motility, and $14 \%$ normal morphology.
\end{abstract}

The submucosal bladder neck collagen injection is a minimally invasive technique that quickly restores anterograde ejaculation and should be considered in the patients with congenital or acquired retrograde ejaculation and for those who did not respond to the medical treatment.

Categories: Urology

Keywords: retrograde ejaculation, bladder neck, collagen injection

\section{Introduction}

Received 10/18/2017

Review began 10/27/2017 Review ended 10/31/2017 Published 11/03/2017

\section{๑) Copyright 2017}

Cakiroglu et al. This is an open access article distributed under the terms of the Creative Commons Attribution License CC-BY 3.0., which permits unrestricted use, distribution, and reproduction in any medium, provided the original author and source are credited.
Retrograde ejaculation (RE) is a condition in which no or minimal antegrade ejaculation occurs, although orgasm is present and all the phases of ejaculation may have been felt by the patient [1]. It accounts not only for male infertility but also impaired sexual satisfaction. The etiology of RE may be congenital, acquired, or idiopathic in origin. The most frequent cause of acquired RE is prostatectomy, whereas congenital RE may be present in cases with posterior urethral valves and meatal stenosis or bladder neck incompetence due to exstrophy [2-3]. It may also occur in the patients with spina bifida. The medical treatment has been used to increase bladder neck tone but with limited efficacy, especially in a fixed anatomical deformity [4-5]. To our knowledge, we report the first successful treatment of RE due to a congenital cause with the transurethral submucosal injection of collagen to the bladder neck.

\section{Technical Report}

A 28-year-old male (height $170 \mathrm{~cm}$, weight $80 \mathrm{~kg}$ ) attended to the urology outpatient clinic with the complaint of scattered urine stream and absence of ejaculation. His previous medical history has been normal, except for urine retention complaints, since his adolescence. On physical examination, both testes were in the scrotum with normal size and consistency, epididymal and ductal structures were normal, the penis was underdeveloped with ventrally hypospadic wide meatus, and the prostate was faintly palpable. The laboratory tests, including hormone profile (follicle stimulating hormone, luteinizing hormone, and testosterone) and routine blood count, were within normal ranges, whereas the semen analysis demonstrated a total absence of ejaculate. Post-ejaculate urine specimens contained a large number of sperms, indicating retrograde ejaculation. Initially, amitriptyline and oral pseudoephedrine were prescribed for four weeks with no positive effect on ejaculation. Subsequently, before the hypospadias repair, a cystoscopy was performed; the prostatic urethra was normal, verumontanum was in orthotopic position, and bladder neck was widely opened (Figure 1a). Nearly $8 \mathrm{ml}$ of dextranomer/hyaluronic acid copolymer (Deflux) was injected into the bladder neck at positions one, five, seven, and 11 o'clock during the same session, which obliterated the large opening of the vesical collum (Figure $1 \mathrm{~b}$-e). 


\section{Cureus}

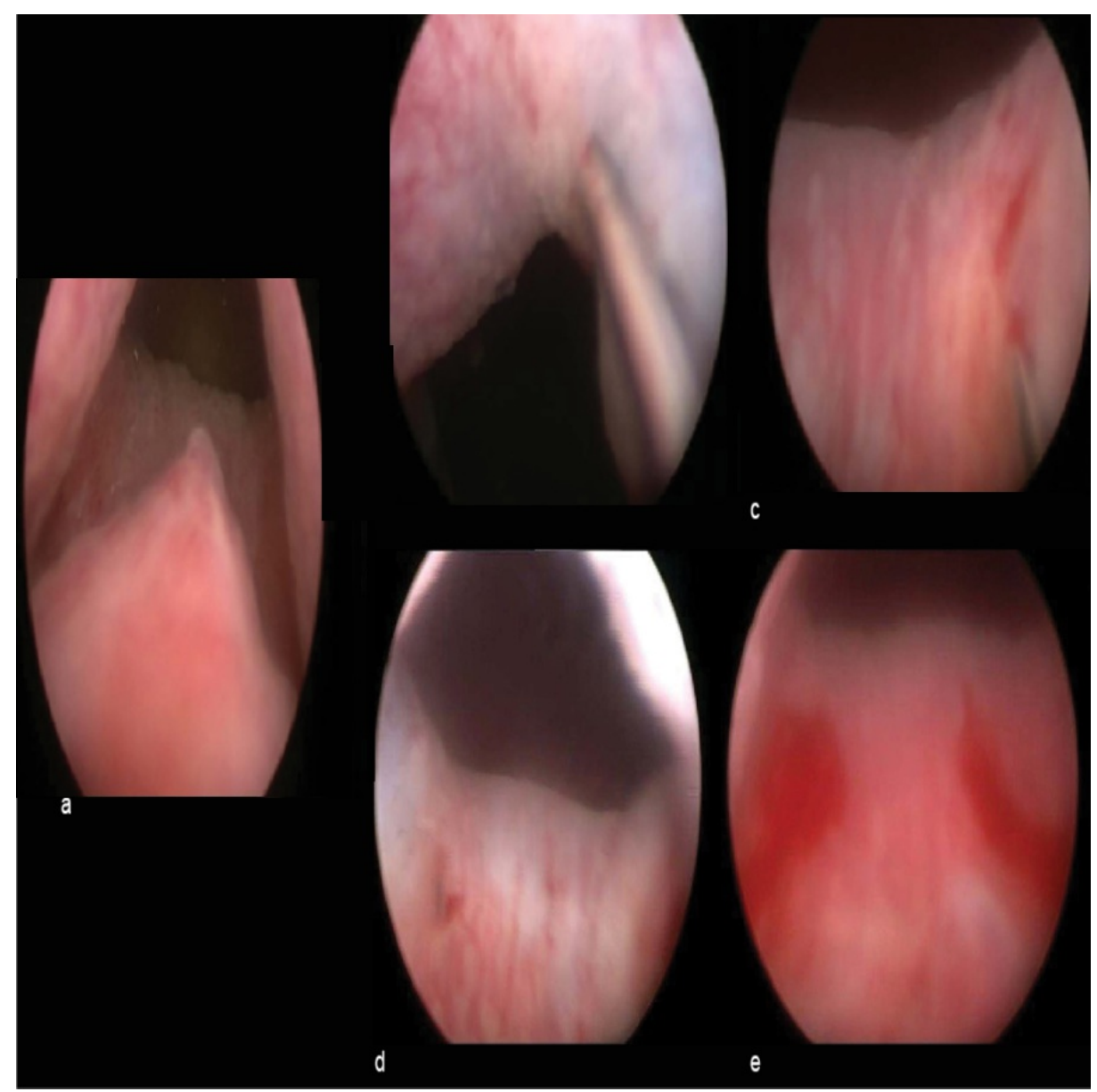

FIGURE 1: Figure representing the positions of the injections and the result.

a: neutral position

b: 1 o'clock position of the injection

c: 5 o'clock position of the injection

d: 7 o'clock position of the injection

e: 11 o'clock position of the injection and the result.

During the first follow-up (four weeks after the surgery), the patient had a normal ejaculate $(2.8 \mathrm{ml})$ after masturbation. The sperm analysis revealed 25 million spermatozoa/ml with $26 \%$ (a) and $57 \%(a+b)$ motility and $14 \%$ normal morphology (Table 1 ).

\section{The sperm analysis at fourth week postoperative}

\begin{tabular}{|c|c|c|c|c|c|}
\hline & Ejaculate volume (ml) & Sperm count (milion/ml) & Morphology percent & Motility (a) percent & Motility $(a+b)$ percent \\
\hline Preoperative & 0 & 0 & 0 & 0 & 0 \\
\hline Postoperative & 2.8 & 25 & 14 & 26 & 57 \\
\hline
\end{tabular}

TABLE 1: Table representing the sperm analysis at fourth week.

\section{Discussion}

The ejaculatory dysfunction is not frequent among infertility causes with an incidence rate of about $2 \%$ [6]. 
Its etiology is multifactorial, which can be acquired or congenital. The most frequent cause of acquired RE is prostatectomy. The bladder neck surgery during childhood is also one among the causes. Oral adrenergic agents have been used to increase the bladder neck tone but with limited efficacy, especially in a fixed anatomical deformity [4-5].

The congenital RE may be present in cases with posterior urethral valves and meatal stenosis or bladder neck incompetence due to exstrophy. It may also occur in the patients with spina bifida. Different congenital abnormalities can occasionally cause RE, e.g. ejaculatory ducts enter into the bladder and very rarely terminate the ectopic ureters or ectopic ureteroceles in the prostatic urethra [7]. For infertility issue, the bladder washing techniques with assisted reproductive techniques also have been successfully used, but they are labor intensive and do not treat the underlying bladder neck incompetence. To date, there are only two cases of collagen injection into the bladder neck in order to correct retrograde ejaculation, both of which were due to the acquired causes [8-9].

The first case underwent VY plasty in childhood, got partial benefit from antihistamines against RE, whereas, after collagen injection, there was normal semen ejaculation. The second RE case was due to the spinal trauma, causing urinary retention and RE has not benefited from imipramine hydrochloride and antihistamines, thus the antegrade ejaculation was ensured following total 6 cc collagen to the bladder neck at four, six, eight o'clock positions. In our case, $8 \mathrm{ml}$ Deflux was injected at positions one, five, seven, and 11 o'clock.

\section{Conclusions}

The aim of the collagen injection, in the present case, was to achieve antegrade ejaculation resulting in a satisfactory sexual relationship and also for the natural fertility. Minimal invasiveness, as well as the immediate efficacy of this technique, deserves consideration after the failure of the conservative treatments in patients with RE due to both congenital or acquired abnormalities.

\section{Additional Information \\ Disclosures}

Human subjects: Consent was obtained by all participants in this study. Animal subjects: All authors have confirmed that this study did not involve animal subjects or tissue. Conflicts of interest: In compliance with the ICMJE uniform disclosure form, all authors declare the following: Payment/services info: All authors have declared that no financial support was received from any organization for the submitted work. Financial relationships: All authors have declared that they have no financial relationships at present or within the previous three years with any organizations that might have an interest in the submitted work. Other relationships: All authors have declared that there are no other relationships or activities that could appear to have influenced the submitted work.

\section{References}

1. Nikolettos N, Al-Hasani S, Baukloh V, et al.: The outcome of intracytoplasmic sperm injection in patients with retrograde ejaculation. Hum Reprod. 1999, 14:2293-96. 10.1093/humrep/14.9.2293

2. Zhao K, Zhang J, Xu A, et al.: Prostatic urethra malformation associated with retrograde ejaculation: a case report. J Med Case Rep. 2016 , 10:373. 10.1186/s13256-016-1150-x

3. Malossini G, Ficarra V, Caleffi G: Retrograde ejaculation. Arch Ital Urol Androl. 1999, 71:185-96.

4. Yavetz H, Yogev L, Hauser R, et al.: Retrograde ejaculation. Hum Reprod. 1994, 9:381-386. 10.1093/oxfordjournals.humrep.a138513

5. Gilja I, Josip J, Radej M, et al.: Retrograde ejaculation and loss of emission: possibilities of conservative treatment. Eur Urol. 1994, 25:226-228. 10.1159/000475288

6. Dubin L, Amelar RD: Etiologic factors in 1294 consecutive cases of male infertility . Fertil Steril. Science Direct (ed): RD, 1971. 22:469-474. 10.1016/S0015-0282(16)38400-X

7. Ekici S, Sinanoglu O, Cubuk R: Ectopic ureterocele: An infrequent cause of retrograde ejaculation and its diagnosis: Case report [Article in Turkish-English]. Turkiye Klinikleri J Med Sci. 2011, 31:1585-7. 10.5336/medsci.2009-16112

8. Reynolds JC, McCall A, Kim ED, et al.: Bladder neck collagen injection restores antegrade ejaculation after bladder neck surgery. J Urol. 1998, 159:1303. 10.1016/S0022-5347(01)63592-4

9. Nagai A, Nasu Y, Watanabe M, et al.: Analysis of retrograde ejaculation using color Doppler ultrasonography before and after transurethral collagen injection. Int J Impot Res. 2004, 16:456-458. 10.1038/sj.ijir.3901202 